\title{
Equilibrium of the simultaneous etherification of isobutene and isoamylenes with ethanol in liquid-phase
}

\author{
R. Soto, C. Fité*, E. Ramírez, R. Bringué, F. Cunill \\ Chemical Engineering Department, Faculty of Chemistry, University of Barcelona, Martí i Franquès 1-11, \\ 08028 Barcelona, Spain
}

\begin{abstract}
A B S T R A C T
The simultaneous etherification of isobutene and isoamylenes with ethanol has been studied using macroreticular acid ion-exchange resins as catalyst. Most of the experiments were carried out over Amberlyst-35. In addition, Amberlyst-15 and Purolite CT-275 were also tested. Chemical equilibrium of four chemical reactions was studied: ethyl tert-butyl ether formation, tert-amyl ethyl ether formation from isoamylenes (2-methyl-1-butene and 2-methyl2-butene) and isomerization reaction between both isoamylenes. Equilibrium data were obtained in a batchwise stirred tank reactor operated at $2.0 \mathrm{MPa}$ and within the temperature range from 323 to $353 \mathrm{~K}$. Experimental molar standard enthalpy and entropy changes of reaction were determined for each reaction. From these data, the molar enthalpy change of formation of ethyl tert-butyl ether and tert-amyl ethyl ether were estimated. Besides, the chemical equilibrium between both diisobutene dimers, 2,4,4-trimethyl-1-pentene and 2,4,4-trimethyl-2-pentene, was evaluated. A good agreement between thermodynamic results for the simultaneous etherification carried out in this work and those obtained for the isolated ethyl tert-butyl ether and tert-amyl ethyl ether systems was obtained.
\end{abstract}

(c) 2013 The Institution of Chemical Engineers. Published by Elsevier B.V. All rights reserved.

Keywords: Simultaneous etherification; Oxygenates; Ethyl tert-butyl ether; Tert-amyl ethyl ether; Chemical equilibrium; Diisobutenes isomerization

\section{Introduction}

In order to reduce hazardous and evaporative gasoline exhausts and from refueling emissions, as well as their environmental impact at the time that engines energetic efficiency is enhanced, new legislation and major efforts have been devoted to fuel reformulation. The European Directive 2009/28/EC promotes the usage of combustibles from renewable resources, such as bioethanol, and the directive 2009/30/EC establishes the main guidelines related to fuel reformulation.

As it is well known, olefins of the $C_{5}$ fraction from oil, mainly the reactive isoamylenes (IA) 2-methyl-1-butene (2M1B) and 2-methyl-2-butene (2M2B), present some disadvantages as components of a gasoline, particularly in tropical zones. This is because these are the olefins with the highest
Reid vapor pressure (RVP), the highest atmospheric reactivity, the highest potential of tropospheric ozone formation (around $90 \%$ ) and these are the largest amount of the olefins present in a gasoline (above $25 \mathrm{wt}$.\% of the $\mathrm{C}_{5}$ fraction from fluid catalytic cracking, FCC) (Rock et al., 1992). Thus, to diminish the impact of their use as fuel components on the environment, the reduction of the content of these compounds by means of either its etherification with primary alcohols or via oligomerization would result in a more suitable alternative than the reduction of the total olefin content of a gasoline.

Oxygenated compounds have been gradually gaining importance in the gasoline market since lead compounds were banned as octane enhancers. The two main types of oxygenates used as high octane additives are alcohols and ethers. Among alcohols, the most widely used is ethanol (EtOH), whereas the main tertiary ethers are methyl tert-buty ether

\footnotetext{
* Corresponding author. Tel.: +34 934034769; fax: +34 934021291.

E-mail addresses: rsotolop7@alumnes.ub.edu (R. Soto), fite@ub.edu (C. Fité), eliana.ramirez-rangel@ub.edu (E. Ramírez), rogerbringue@ub.edu (R. Bringué), fcunill@ub.edu (F. Cunill).

Received 25 July 2013; Received in revised form 30 October 2013; Accepted 13 November 2013

0263-8762/\$ - see front matter @ 2013 The Institution of Chemical Engineers. Published by Elsevier B.V. All rights reserved. http://dx.doi.org/10.1016/j.cherd.2013.11.012
} 


\section{Nomenclature}

$a, b, c, d$ temperature dependence parameters of thermodynamic functions

$a_{j}, b_{j}, c_{j}, d_{j}$ temperature dependence coefficients of heat capacity expression for compound $j$

$a_{j}^{\prime} \quad$ activity of compound $j$

$C_{p j}^{\circ} \quad$ molar heat capacity of compound $j$ in the liquid phase $(J /(\mathrm{mol} \mathrm{K}))$

$\Delta_{f} G_{j}^{\circ} \quad$ liquid-phase standard molar enthalpy change of formation of compound $j(\mathrm{~kJ} / \mathrm{mol})$

$\Delta_{f} H_{j}^{\circ} \quad$ liquid-phase standard molar enthalpy change of formation of compound $\mathrm{j}(\mathrm{kJ} / \mathrm{mol})$

$\Delta_{r} G_{i}^{\circ} \quad$ standard Gibbs free energy change of reaction $i$ in the liquid phase $(\mathrm{kJ} / \mathrm{mol})$

$\Delta_{r} H_{i}^{\circ} \quad$ standard molar enthalpy change of reaction $i$ in the liquid phase $(\mathrm{kJ} / \mathrm{mol})$

$\Delta_{r} S_{i}^{\circ} \quad$ standard molar entropy change of reaction $i$ in the liquid phase $\left(\mathrm{JK}^{-1} \mathrm{~mol}^{-1}\right)$

$I_{H} \quad$ van't Hoff integration constant (dimensionless)

$I_{K} \quad$ Kirchoff integration constant $(J / \mathrm{mol})$

$\mathrm{K}_{\mathrm{i}}$ thermodynamic equilibrium constant of reaction $i$ (dimensionless)

$K_{x i} \quad$ equilibrium constant of reaction $i$ based on molar fractions (dimensionless)

$K_{\gamma i} \quad$ activity coefficients ratio of reaction $i$

$\mathrm{K}_{\Gamma \mathrm{i}} \quad$ Poynting correction factor of reaction $i$ (dimensionless)

$n \quad$ number of mole (mol)

$P \quad$ pressure (bar)

$R \quad$ gas constant, $8.31447 \mathrm{~J} /(\mathrm{mol} \mathrm{K})$

$R_{A / O} \quad$ initial molar ratio alcohol to olefins

$R_{C 4 / C 5} \quad$ initial molar ratio between $C_{4}$ and $C_{5}$ isoolefins

$\mathrm{S}_{g} \quad$ specific surface area $\left(\mathrm{m}^{2} \mathrm{~g}^{-1}\right)$

$S_{j}^{\circ} \quad$ absolute entropy of compound $j\left(\mathrm{JK}^{-1} \mathrm{~mol}^{-1}\right)$

$\mathrm{T}$ temperature $(\mathrm{K})$

$t \quad$ time (min)

$\mathrm{T}_{\max } \quad$ maximum working temperature $(\mathrm{K})$

$\mathrm{V}_{j} \quad$ molar volume of compound $j\left(\mathrm{~L} \mathrm{~mol}^{-1}\right)$

$\mathrm{W}_{\text {cat }} \quad$ mass of dry catalyst (g)

$X_{j} \quad$ relative conversion of reactant $j$

$x_{j} \quad$ molar fraction of compound $j$

\section{Subscript}

$0 \quad$ initial

\section{Greek letters}

$\gamma_{j} \quad$ activity coefficient of compound $j$

$v_{j i} \quad$ stoichiometric coefficient of compound $j$ in reaction $i$

(MTBE), ethyl tert-butyl ether (ETBE), tert-amyl methyl ether (TAME) and tert-amyl ethyl ether (TAEE). These ethers can be obtained by means of the addition of primary alcohols to tertiary olefins over acid catalysts (Dogu and Varisli, 2007). MTBE and TAME are produced from the reaction of methanol $(\mathrm{MeOH})$ with isobutene (IB) and IA (2M1B and 2M2B), respectively. Analogous reactions of these olefins with EtOH lead to ETBE and TAEE production.

Generally, ethers are preferred rather than alcohols due to their blending characteristics, since they are more like conventional constituents hydrocarbons of a gasoline (Kitchaiya and
Datta, 1995). Due to azeotropes formation, alcohols blending normally confer a higher RVP, what implies more evaporative and exhaust emissions, and also a possible phase separation due to the water presence within the system (Arteconi et al., 2011). Despite the choice of some countries like the US and Brazil of a direct blending of EtOH or bioethanol, mainly for economic advantages, it has some drawbacks such as: high vapor pressure, high latent heat of vaporization, possibility to introduce water in the system, less energetic content and less enthalpy of combustion compared to ethers. As a result, specific fuel consumption induced by direct blending of EtOH is around $40 \%$ higher than that induced by tertiary ethers blending (mainly ETBE and TAEE) (Cataluña et al., 2008). Likewise, its high oxygen content can promote nitrogen oxides $\left(\mathrm{NO}_{x}\right)$ formation or limit the amount of blended additive in order to fulfill the maximum legislated oxygen content (Kiatkittipong et al., 2008).

It is worth noting that, despite being currently the tertiary ether most widely produced, MTBE usage was banned in some states of the US such as California, due to its toxicity, its water solubility and consequently, its potential danger to pollution of freatic waters (Ahmed, 2001). On the other hand, ETBE production has experienced fast global growth in the last two decades, especially in Europe, due to the ease of revamping of MTBE existent plants. ETBE is synthesized industrially through the reaction between IB and ETOH in liquid phase, usually catalyzed by macroporous sulfonic acid resins at a temperature below $353 \mathrm{~K}$ under pressurized conditions (Yee et al., 2013). Nowadays, TAEE is not produced industrially at large scale, but it could become an interesting alternative since both ETBE and TAEE can be obtained from bioethanol, a renewable resource.

Several authors have studied the etherification of $\mathrm{C}_{5}-\mathrm{C}_{8}$ alkenes with $\mathrm{C}_{1}-\mathrm{C}_{4}$ alcohols (Karinen et al., 2001a; Kiatkittipong et al., 2011; Oktar et al., 1999a). Thermodynamic and kinetic parameters of MTBE (Gómez et al., 1997; Iborra et al., 2002; Izquierdo et al., 1994) and TAME (Krause and Hammarström, 1987; Mao et al., 2008; Muja et al., 2005; Rihko and Krause, 1995; Rihko et al., 1997; Serdá et al., 1995; Solà et al., 1997; Syed et al., 2000) production reactions are available in literature, and also the influence of mass transfer effects (Pääkkönen and Krause, 2003). Similarly, kinetics of ETBE (Fité et al., 1994; Françoisse and Thyrion, 1991; Iborra et al., 2002; Izquierdo et al., 1994; González, 2011; Solà et al., 1995; Vila et al., 1993) and TAEE (Aiouache and Goto, 2003; Boonthamtirawuti et al., 2009; Boz et al., 2005; Boz and Dogu, 2005; Bozga et al., 2008; Cruz et al., 2007; Linnekoski et al., 1997; Oktar et al., 1999b; Zhang et al., 1997) formation reactions have been widely studied for the isolated systems in previous works. Activation energies and kinetic constants values have been published, concluding that a Rideal-Eley mechanism fits better for the liquid phase ETBE synthesis from IB and EtOH and that a Langmuir-Hinshelwood model describes better the liquid phase reaction between IA and EtOH to produce TAEE. Thermodynamics of these reactions for the isolated systems has also been studied and equilibrium constants, enthalpies and entropies of formation and reaction have been determined (Fitó and Linnekoski, 2008; Gómez et al., 1997; Izquierdo et al., 1994; Jensen and Datta, 1995; Kitchaiya and Datta, 1995; Linnekoski et al., 1998, 1999; Muja et al., 2005; Rihko and Krause, 1993; Rihko et al., 1994; Sharonov et al., 1995).

The use of bioethanol as reactant entails a potential source of water into the system, hence it is worthy to study the effect 
of water on the product distribution and on the activity performance of the catalyst, through the addition of known amounts of water to the initial reactant mixture. This effect has already been studied for the isolated ETBE and TAEE systems over acid ion-exchange resins (Cunill et al., 1993; Degirmenci et al., 2009; Fité et al., 1994; Fitó and Linnekoski, 2008; González, 2011; Linnekoski et al., 1998; Yang et al., 2000), and it was concluded that water affects the catalytic activity and selectivity toward desirable products, because water competes for the catalyst active sites with the main reactants, which reduces the number of available active sites for ether formation. Since water is highly polar, it promotes the swelling of catalyst, what improves the accessibility of reactants to inner active sites. Moreover, water can solvate the sulphonic group protons, what destroys the hydrogen bridge structure formed between them and diminishes their acid strength. Therefore, water presence induces lower reaction rates and favors side reactions of hydration of olefins to produce tertiary alcohols, such as tert-butyl alcohol (TBA) and tert-amyl alcohol (TAA) from the hydration of $C_{4}$ and $C_{5}$ isoolefins, respectively.

Although in the literature several studies have been devoted to these etherification reactions separately, and there is even some research regarding the simultaneous etherification of a iso-olefin with two primary alcohols (Gómez et al., 1997; Karinen et al., 2001a), as far as our knowledge there is no evidence in the literature about the simultaneous etherification of two tertiary olefins (such as IB and IA) with a primary alcohol, and more specifically in the presence of water. Thus, it is interesting to study it from a kinetic and thermodynamic point of view, in order to find out the performance of the simultaneous process. Furthermore, simultaneous etherification of isobutene and isoamylenes could constitute the integration of two etherification processes at industrial scale, which would mean savings in installation, operation and maintenance costs. In fact, the etherification of gasolines from FCC with ethanol and methanol has already been studied (Cataluña et al., 2008; Rock and Korpelshoek, 2008; Kiatkittipong et al., 2008, 2009, 2011; Rihko and Krause, 1996) showing as feasible the technique of the simultaneous etherification of several olefins.

The aim of this work is to study the simultaneous production of ETBE and TAEE by means of the reaction of IB and IA with EtOH over acidic ion exchange resins as catalyst. The experimental determination of thermodynamic properties of these reactions also constitutes a key factor in order to contrast them with the reported values for the separated ETBE and TAEE etherification systems.

\section{Experimental}

\subsection{Experimental setup}

Experimental runs were carried out in a $200 \mathrm{~cm}^{3}$ stainlesssteel jacketed batch reactor equipped with a six-blade magnetic stirrer (Autoclave Engineers, USA). The stirrer speed was set at $500 \mathrm{rpm}$ to avoid the influence of external mass transfer effects (Umar et al., 2008; Linnekoski et al., 1997). The reaction temperature range was $323-353 \mathrm{~K}$, controlled within $\pm 0.1 \mathrm{~K}$ by a thermostatic bath mixture (33 vol.\% of 1,2propanediol, 67 vol. $\%$ of water). The reactor pressure was kept with nitrogen at $2.0 \mathrm{MPa}$ to maintain the liquid phase over the reaction. More detailed information about the experimental setup is described elsewhere (Cruz et al., 2005).

\begin{tabular}{lccc}
\hline \multicolumn{3}{l}{ Table 1 - Physical properties of catalysts. } \\
Catalyst & $\begin{array}{c}\text { Acid capacity } \\
\left(\text { eq H } \mathrm{H}^{+} / \mathrm{kg}\right)\end{array}$ & $\mathrm{S}_{\mathrm{g}}\left(\mathrm{m}^{2} \mathrm{~g}^{-1}\right)^{\mathrm{a}}$ & $\mathrm{T}_{\max }(\mathrm{K})$ \\
\hline A-35 & 5.32 & 34.0 & 423 \\
A-15 & 4.81 & 42.0 & 393 \\
CT-275 & 5.20 & 21.8 & 418 \\
\hline
\end{tabular}

a BET method.

\subsection{Reactants}

Reactants consisted of an IA mixture containing 2M2B (96\% G.C.) and 2M1B (4\% G.C.) (TCI Europe, Belgium), isobutylene (>99.9\% G.C.) (Air Liquide, Spain) and EtOH absolute dry (max. 0.02 wt.\% water) (Panreac, Spain) and water.

Some chemical standards were used for analytical procedures: 2,4,4-trimethyl-1-pentene (TMP-1, >98.0\% G.C.) and 2,4,4-trimethyl-2-pentene (TMP-2, >98\% G.C.) (Fluka, Buchs, Switzerland), TAA (>98.0\% G.C.) (TCI Europe, Belgium), TBA (>99.7\% G.C.) (TCI Europe, Belgium), ETBE (>99.0\% G.C.) (TCI Europe, Belgium), 2M1B (>99.0\% G.C.) (TCI Europe, Belgium) and 2M2B (>99\% G.C.) (Sigma-Aldrich, Germany). TAEE was obtained in our laboratory with a minimum purity of $98.5 \%$ G.C. Dimers $\mathrm{C}_{10}$ were also synthesized in our laboratory $(>99 \%$ G.C.). Due to the difficulty of obtaining pure $\mathrm{C}_{9}$ codimers, an intermediate response factor between $C_{8}$ and $C_{10}$ dimers was used for its calibration.

\subsection{Catalysts}

Amberlyst 35 (A-35, Rohm \& Hass, Chauny, France) was used as the main acidic macroreticular resin catalyst of this study. In addition, two similar catalysts, Amberlyst 15 (A-15, Rohm \& Hass, Chauny, France) and Purolite CT-275 (CT-275, Purolite Ltd., Pontyclun, UK), were tested at $353 \mathrm{~K}$ with an initial molar ratio of alcohol to olefins (IB and IA joined together) of $R_{A / O}=0.5$, and an initial molar ratio of $C_{4}-C_{5}$ olefins of $R_{C 4 / C 5}=1$ in equilibrium experiments in order to confirm that the chemical equilibrium composition does not depend on the used catalyst. Catalyst bead sizes distribution was used as commercially supplied. The main physical and structural properties of the catalysts are given in Table 1.

In the pretreatment, the catalyst was dried for $2.5 \mathrm{~h}$ in an atmospheric oven at $383 \mathrm{~K}$ and subsequently $15 \mathrm{~h}$ in a vacuum oven at $383 \mathrm{~K}$. The remaining water content in the dried catalyst was measured by Karl Fisher titration method for different samples of A-35 with a result of less than $3.5 \mathrm{wt} . \%$.

\subsection{Analysis method}

Samples from the reaction medium were taken inline through a sampling valve (Valco A2CI4WE.2, VIVI AG International, Schenkon, Switzerland) which injected $0.2 \mu \mathrm{L}$ of pressurized liquid into a gas-liquid chromatograph (Agilent 6890 GC, Madrid, Spain) equipped with a capillary column (HPPONA 19091S-001, Hewlett Packard, Palo Alto, USA; 100\% dimethylpolysiloxane, $50.0 \mathrm{~m} \times 0.2 \mathrm{~mm} \times 0.5 \mu \mathrm{m}$ nominal) able to work from 213 to $623 \mathrm{~K}$. A mass selective detector (HP $5973 \mathrm{~N}$ MS) coupled to the GC was used to identify and quantify the reaction system components. The injector temperature was set to $523 \mathrm{~K}$, the electron source of the mass detector was set to $503 \mathrm{~K}$, and the quadrupole was set to $423 \mathrm{~K}$. The oven temperature was programmed with a $10 \mathrm{~min}$ hold at $304 \mathrm{~K}$, 
followed by a $20 \mathrm{~K} / \mathrm{min}$ ramp, from 304 to $353 \mathrm{~K}$. A second hold of $5 \mathrm{~min}$ at $353 \mathrm{~K}$ followed by a second temperature ramp of $60 \mathrm{~K} / \mathrm{min}$ from 353 to $493 \mathrm{~K}$; this final temperature was held for $10 \mathrm{~min}$. Helium (Abelló-Linde, Barcelona, Spain) with a minimum purity of $99.998 \%$ was used as carrier gas. C 9 dimers by one side and $\mathrm{C}_{10}$ by another were lumped together each as a group of dimers. Neither trimers nor higher oligomers were detected under the conditions of this study.

\subsection{Procedure}

The molar ratio alcohol to olefins $\left(R_{\mathrm{A} / \mathrm{O}}\right)$ and the molar ratio between olefins $\left(R_{C 4 / C 5}\right)$, were varied between 0.5 and 2 . An initial amount of water of approximately $1 \mathrm{wt} . \%$ of the initial reactant mixture was added to all experiments in order to monitor TBA and TAA formation.

The assayed temperature range was from 323 to $353 \mathrm{~K}$. Experiments at 343 and $353 \mathrm{~K}$ were carried out using $4 \mathrm{~g}$ of dried catalyst, and experiments at $333 \mathrm{~K}$ with $8 \mathrm{~g}$ in order to reach chemical equilibrium composition during the experiment run. Also for this reason, experiments at $323 \mathrm{~K}$ were performed starting from the final reaction mixture of the equilibrium experiments at $333 \mathrm{~K}$, because at $323 \mathrm{~K}$ reaction rates are very low.

Initially, ethanol, water and the catalyst were placed into the reactor and heated up until the system reached the desired temperature by means of the thermostatic bath. Both isoamylenes and isobutene were introduced, previously weighted, in a calibrated buret and pressurized to $1.5 \mathrm{MPa}$ with nitrogen. When the desired temperature of the reactor was reached, the reacting mixture of olefins, which was at room temperature, was shifted from the buret into the reactor. Then, the reactor was heated again until the desired temperature and the pressure was set to $2.0 \mathrm{MPa}$ with nitrogen to ensure the liquid phase. During this time lag some reactants conversion took place, since reactants and catalyst were in contact, but in a small extent and a not precisely known temperature evolution. Therefore, the instant at which the system reached again the desired temperature was considered as starting time of reaction, and a sample was taken from the reactor to determine the initial mixture composition. From then on, the reactor operated isothermally. Subsequently, samples were analyzed at different instants until no further change in composition was observed, what indicated that chemical equilibrium had been reached (typically after $6-8 \mathrm{~h}$ of running).

\section{Results and discussion}

\subsection{Description of the reaction system}

In the etherification of industrial $C_{4}$ fraction over acid ion exchange resins, IB is the most reactive component at the temperature range of this study. The 1-butene, cis-2-butene and trans-2-butene reacts at higher temperatures and molar ratios alcohol to olefin lower than 1.3, whereas $\mathrm{C}_{4}$ paraffins (butanes) do not react (Vila et al., 1994). Only tertiary olefins react in the etherification reactions under the usual process conditions, the rest of olefins from the $C_{5}$ fraction, as well as paraffins or naphtenes, remaining unreactive (Krause and Hammarström, 1987). Among the three $C_{5}$ methylbutene isomers, 2 M1B gives the fastest reaction, and $2 \mathrm{M} 2 \mathrm{~B}$ reacts $2-5$ times more slowly depending on the alcohol, whereas 3-methyl-1-butene (3M1B)

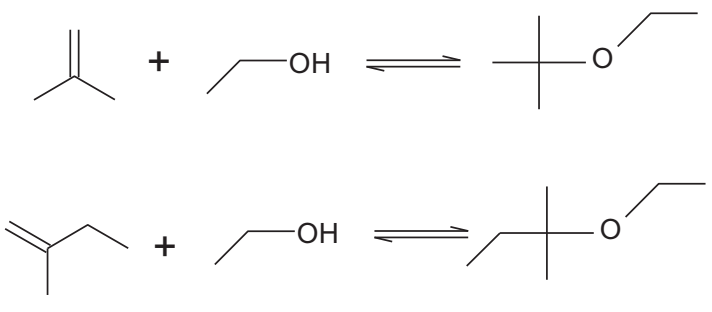

[R1]

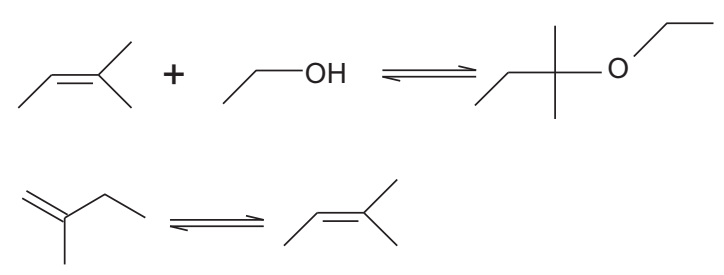

Fig. 1 - Main reactions scheme.

does not react. As a result, only 2M1B and 2M2B were used as $\mathrm{C}_{5}$ reactive olefins.

In the present reaction system, several reactions can take place simultaneously. Among them, the following reversible reactions have been studied:

Fig. 1 Reaction R1 is the etherification reaction between IB and EtOH to form ETBE. R2 and R3 are etherification reactions of IA (2M1B and 2M2B, respectively) with $\mathrm{EtOH}$, to produce TAEE, and R4 is the IA double bond isomerization reaction between 2M1B and 2M2B. The reversible hydration reactions of IB and IA with the water present in the reactant mixture and within the catalyst to produce the correspondent tertiary alcohols, TBA and TAA respectively, also take place simultaneously. However, they were not studied as deeply as R1 to R4 owing to the low amount of tertiary alcohols detected under the assayed conditions (always less than 3.0 and $2.2 \mathrm{wt} . \%$, respectively), and, consequently, they were considered as side reactions. Moreover, reversible DEE formation reaction via EtOH dehydration is expected to occur in low extension under the conditions of this study (Kiviranta-Pääkkönen et al., 1998), but the maximum content of detected DEE was always lower than $0.05 \%$ GC, and, therefore, DEE was not considered in the further analysis. In addition to the mentioned reversible reactions, $C_{8}$ and $C_{10}$ dimers can be formed as the product of the irreversible dimerization reactions between olefins (IB and IA), especially at the highest temperature and in olefin excess. $C_{9}$ codimers can also be obtained thereof. The amount of dimers was found to increase steadily and linearly with time, but slowly (it never overcame $2.5 \mathrm{wt} . \%$ ), so reactions R1-R4 could be considered to be at pseudo-equilibrium at the final time of each experimental run.

The chemical equilibrium of the isomerization reaction between $\mathrm{C}_{8}$ dimers (TMP-1 and TMP-2) is also known to take place (Karinen et al., 2001b). This double bond isomerization reaction of trimethylpentenes does not follow the usual rule of the chemical equilibrium of alkenes, which typically favors the species with the double bond further from the end of the carbon chain, as is the case of the isoamylenes isomerization reaction (Solomons and Fryhle, 2000). But it follows an opposite trend owing to the size of tert-butyl group, which produces a highly crowded part in the molecule of TMP-2 and promotes then the elimination of the proton from the methyl group in the other part of the molecule (Karinen et al., 2001b). In the case of TMP-1, the tert-butyl group is further away in the position $\beta$ to the double bond and the largest substituent is in the cis position with hydrogen, which occupies much less 


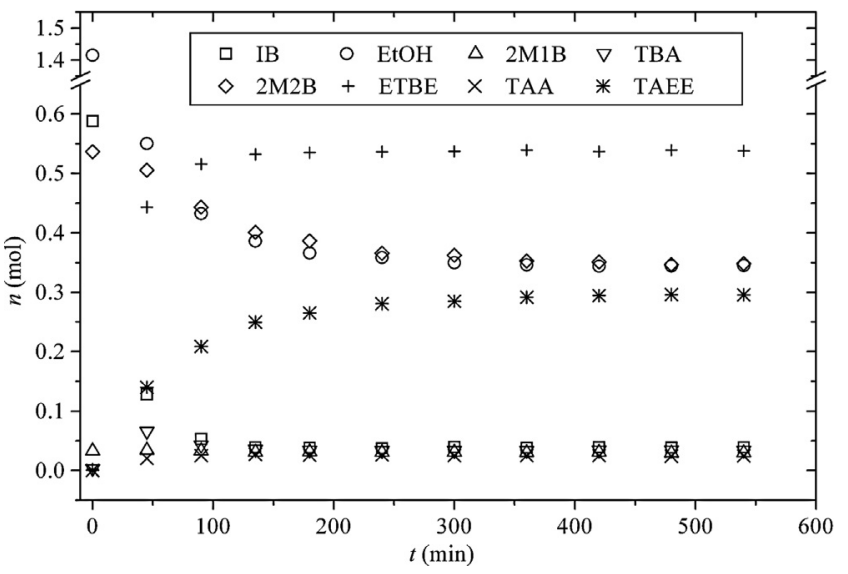

Fig. 2 - Model experiment carried out at $333 \mathrm{~K}$, $R_{\mathrm{A} / \mathrm{O}}=1$ and $R_{\mathrm{C} 4 / \mathrm{C} 5}=1$, with $8 \mathrm{~g}$ of catalyst $\mathrm{A}-35$.

space. The chemical equilibrium of TMP-1 and TMP-2 has not been deeply studied in this work, because the conditions of the experiments were not designed for it. However, some aspects will be further deduced from the obtained results.

In Fig. 2, a model experiment over $8 \mathrm{~g}$ of $\mathrm{A} 35$ at $333 \mathrm{~K}, \mathrm{R}_{\mathrm{A} / \mathrm{O}}=1$ and $R_{C 4 / C 5}=1$ is depicted. It can be seen that ETBE production reaction was practically at chemical equilibrium state after $180 \mathrm{~min}$, whereas the TAEE system needed two times that period to reach equilibrium. Since the amount of formed ETBE was always larger than that of TAEE, it can be concluded that IB is more reactive with EtOH than IA. IB conversion at the steady state was approximately the double of IA conversion. The number of moles of tertiary alcohols formed was very similar for TBA and TAA, and both reached quickly the chemical equilibrium state, normally in less than 100 min of reaction.

In order to evaluate the experimental error, some experiments were replicated in triplicate, more specifically those at $R_{A / O}=1$ and $R_{C 4 / C 5}=1$ at each temperature. The mean values of equilibrium constants and the associated standard errors have been included in the Supplementary Data section. The results were found to be reproducible. In replicated experiments, the standard error of the average equilibrium constant was always lower than $5 \%$, except for $K_{1}$ and $K_{2}$ at $323 \mathrm{~K}$, where the standard error was 9 and $7 \%$, respectively. The main cause of the deviation is the low olefin content (IB and 2M1B) at equilibrium at the lowest temperature, which led to higher differences between calculated values. Therefore, omitting this specific circumstance, experiments were globally considered as reproducible.

\subsection{Effect of catalyst load}

As pointed out above, the catalyst load was varied from $4 \mathrm{~g}$ in experiments at $343 \mathrm{~K}$ and $353 \mathrm{~K}$ to $8 \mathrm{~g}$ in experiments at 333 and $323 \mathrm{~K}$ in order to shorten the length of the experiment at lower temperatures. Hence, the effect of the catalyst load (using $4 \mathrm{~g}$ and $8 \mathrm{~g}$ ) was studied on commercial bead size distribution for A-35 at $333 \mathrm{~K}$. To allow the comparison for the different catalyst loads, the contact time $\mathrm{W}_{\text {cat }} \cdot t \cdot n_{\mathrm{EtOH}, 0}^{-1}$ was used instead of time $t$. Fig. 3 shows the reactants conversion versus contact time for the two used catalyst loads.

From Fig. 3, it can be observed that, for each considered reactant conversion, evolution for both catalysts loads overlaps when it is plotted versus the contact time. Hence, no significant effect of the catalyst loading was observed under these conditions within the experimental error. Therefore,

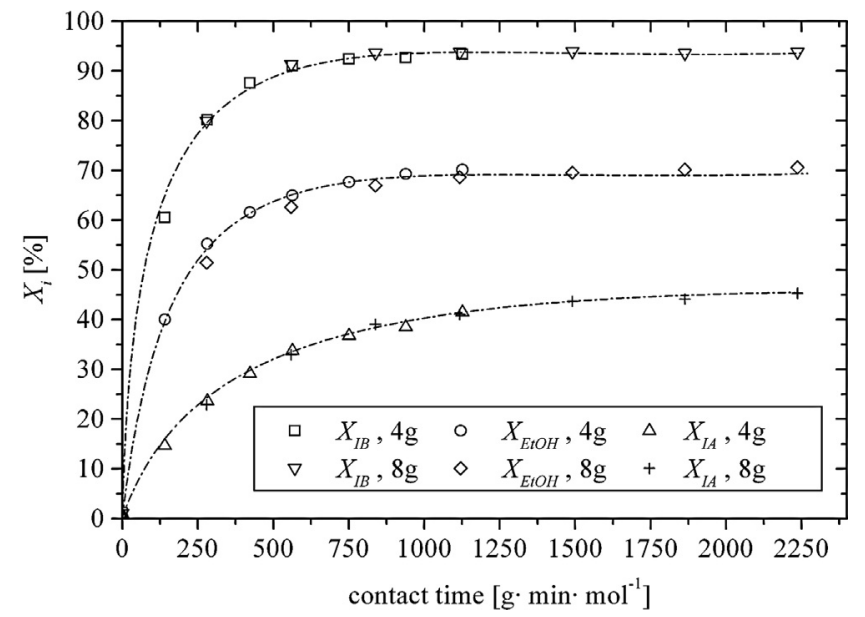

Fig. 3 - Evolution of the reactants conversion with respect to the contact time $\left(W_{\mathrm{cat}} \cdot t \cdot n_{\mathrm{EtOH}, 0}^{-1}\right)$ for different catalyst loads of A-35. Experimental conditions were $333 \mathrm{~K}$, $R_{A / O}=1$ and $R_{C 4 / C 5}=1$.

hereinafter both catalyst loads of 4 and $8 \mathrm{~g}$ will be used as appropriate for the experiment duration.

\subsection{Equilibrium constants}

The chemical equilibrium of reactions R1 to R4 was studied. The rest of the reactions were not studied due to the low amount of the involved products detected, namely DEE, TBA and TAA.

It is worth noting that only two of reactions R2, R3 and R4 are stoichiometrically independent in the TAEE formation reaction system. For instance, addition of reactions R3 and $\mathrm{R} 4$ gives reaction $\mathrm{R} 2$. Thus, in relation with the equilibrium constants, it can be written:

$K_{2}=K_{3} K_{4}$

Considering the nonideality of the mixture, mainly due to the presence of alcohols and water, activity coefficients of compounds, $\gamma_{j}$, were estimated by means of the UNIFACDortmund predictive method (Gmehling et al., 1993, 1998; Lohmann et al., 2001; Weidlich and Gmehling, 1987). This method was chosen because it gave good results for most of the studies reported before for the isolated etherification systems and aiming to compare results properly. Activity coefficients for alcohols are normally larger than 3 (at low mole fractions), and for ethers (slightly non ideals) and olefins they are close to the unity (Hamid and Ali, 2004). In general, the thermodynamic equilibrium constant $K_{i}$, for the liquid-phase reaction $i$ of a nonideal system with $S$ species can be expressed as follows:

$K_{i} \equiv \prod_{j=1}^{s}\left(a_{j}^{\prime}\right)_{e i}^{v_{j}}=\left(\prod_{j=1}^{s}\left(\gamma_{j}\right)_{e}^{v_{j}}\right)_{i}\left(\prod_{j=1}^{s}\left(x_{j}\right)_{e}^{v_{j}}\right)_{i} \equiv K_{\gamma_{i}} K_{x_{i}}$

where $K_{x i}$ is the equilibrium constant of reaction $i$ in terms of molar fractions and $K_{\gamma i}$ is the related equilibrium constant in terms of activity coefficients.

The table in the Supplementary data section shows the experimental conditions of the performed experiments, the calculated equilibrium constants and the experimentally obtained $K_{x i}$ and $K_{\gamma i}$ for the etherification reactions of olefins 


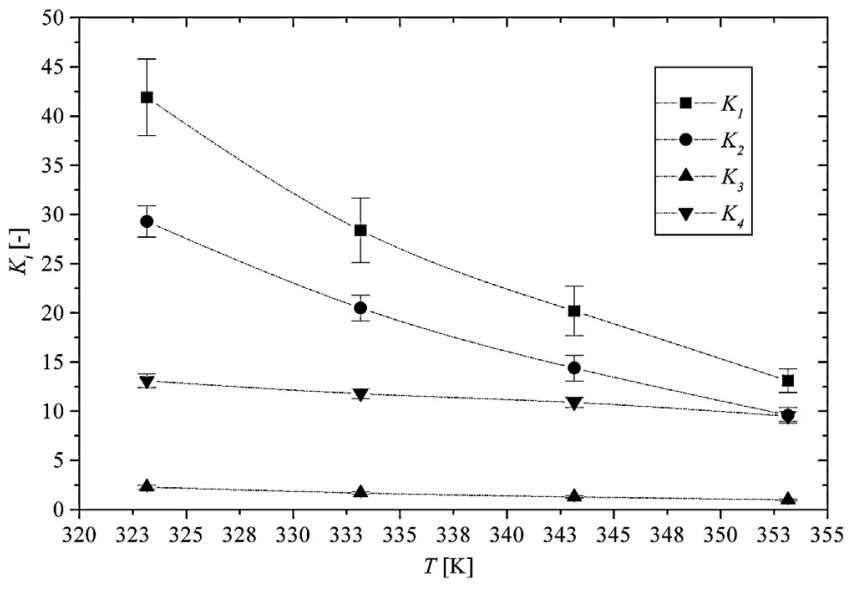

Fig. 4 - Temperature dependence of the thermodynamic equilibrium constants for reactions R1-R4. Error bars refer to a $95 \%$ confidence interval.

with $\mathrm{EtOH}$ and the IA isomerization reaction. Obtained values for $\mathrm{K}_{\mathrm{xi}}$ at different temperatures ranged from 236.0 to 20.4, from 183.3 to 14.4 , from 15.1 to 1.6 and from 14.4 to 8.3 for R1, R2, R3 and R4, respectively. Moreover, $K_{x i}$ was found to decrease when $R_{C 4 / C 5}, R_{A / O}$ and temperature increased. On the other hand, $K_{\gamma i}$ showed an opposite trend in its relationship with the different initial molar ratios and temperature with the exception of R4, where it is difficult to establish a clear relationship between $K_{\gamma 4}$ and temperature, $R_{\mathrm{C} 4 / \mathrm{C} 5}$ or $R_{\mathrm{A} / 0} . K_{\gamma \mathrm{i}}$ ranged at the assayed temperatures from 0.178 to 0.636 , from 0.170 to 0.611 , from 0.168 to 0.608 and from 1.006 to 1.019 for R1, R2, R3 and R4, respectively. Values of $K_{\gamma i}$ for reactions R1, R2 and R3 (reactions where EtOH is a reactant) were significantly different from unity, especially at low $R_{A / O}$, which confirms the nonideality of the system. The values of $\mathrm{K}_{\gamma 4}$, for the IA isomerization reaction, were very close to the unity, as expected, since in this reaction only the two olefins are involved, which are very similar and, therefore, they should present similar activity coefficient.

As mentioned above, irreversible olefins dimerization took place at $R_{A / O}=0.5$ and at high temperatures (343-353 K) which could make the study of the chemical equilibrium difficult as the actual equilibrium state composition would not be reached until reactants consumption. Notwithstanding, dimers formation was so slow compared to isomerization and etherification reactions at the assayed temperatures that equilibrium constants of the main etherification reactions could be evaluated assuming a pseudo-equilibrium state. Moreover, isomerization reactions are known to take place faster than etherification reactions. Consequently, olefins were consumed slowly to form dimers, allowing a quick readjustment of the compositions for the etherification and isomerization reactions and maintaining a pseudo-equilibrium state.

In Fig. 4 the relationship between the average values of experimentally obtained thermodynamic equilibrium constants and temperature for each reaction is plotted for A-35. Results obtained for A-15 and CT-275 were included neither to obtain the values plotted in Fig. 4 nor in the subsequent determination of thermodynamic properties. However, it was confirmed that experimentally obtained equilibrium constants for A-35, A-15 and CT-275 were very similar under the same conditions (see Supplementary data section), as expected considering the well-known fact that $K_{i}$ value is independent of the used catalyst.
The relatively larger error of $K_{1}$ in the ETBE formation reaction is attributed to the low IB content at equilibrium, due to the high conversion of IB at low temperatures. All four thermodynamic equilibrium constants decrease monotonically with temperature, as expected for exothermic reactions. As for kinetics, at the highest temperature, the highest reaction rate for ethers formation was observed, but also the lower amount of ethers formed at chemical equilibrium. R1 was the first reaction that reached the chemical equilibrium. Concerning etherification reactions, $K_{1}$ was always higher than $K_{2}$ and $\mathrm{K}_{3}$ at the same temperature, what suggests that the equilibrium constant decreases when the size of the olefin molecule increases. This fact is consistent with the results reported in published studies in which different alcohols were used in the reaction with isobutene (Izquierdo et al., 1994; Karinen et al., 2001a). It was concluded that the equilibrium constant value decreased when the alcohol size increased. As a consequence, it can be said that the higher the reactant size, the lower the equilibrium constant value is observed for these etherification reactions.

ETBE synthesis reaction (R1) presented the highest exothermicity since $K_{1}$ showed a relatively larger decrease at increasing temperature compared to the rest of reactions. As $K_{1}, K_{2}$ and $K_{3}$ decreased monotonically with increasing temperature, less ETBE and TAEE were produced at higher temperatures. $\mathrm{K}_{4}$ decreased as well with increasing temperature, but in a much lesser extent than the ethers formation reactions because of the smaller exothermicity of this reaction. Since $\mathrm{K}_{4}$ decreased at slower rate with temperature, it can be said that isomerization conversion of $C_{5}$ isoolefins (where $2 \mathrm{M} 1 \mathrm{~B}$ is converted to $2 \mathrm{M} 2 \mathrm{~B}$ ) decreases more slightly with the rise of temperature, whereas etherification conversion for both olefins, IA and IB, decreases in a significant extension. In fact, it has been already contrasted in the isolated TAEE formation system from IA that a lower temperature favors etherification reactions, whereas a higher temperature favors the isoamylenes isomerization reaction (Izquierdo et al., 1994; Kitchaiya and Datta, 1995; Linnekoski et al., 1998; Rihko et al., 1994).

The values in the Supplementary data section and Fig. 4 show that TAEE synthesis from 2M2B was less favorable than its synthesis from $2 \mathrm{M} 1 \mathrm{~B}$, since $K_{3}$ was always lower than $K_{2}$. This fact might be related to the thermodynamic stabilities of both isoamylenes. The relative stability of an olefin is determined by the number of alkyl groups bonded to the carbon atoms with double bonds, the olefins being more stable as that number increases (Solomons and Fryhle, 2000). Therefore, 2M2B should be thermodynamically more stable than 2M1B. With regard to the IA isomerization reaction equilibrium constant, it was slightly dependent of temperature.

Theoretical equilibrium constants values can be estimated from the thermodynamic data available in literature using the liquid phase standard molar enthalpy and Gibbs free energy changes of formation of the components involved in each reaction. The accuracy in the calculation of the equilibrium constants following this procedure is highly sensitive to the quality of the thermodynamic data, especially for reactions with moderate standard Gibbs free energy changes, as it is the case for reversible reactions (Ferreira and Loureiro, 2004). Experimental data for the liquid-phase heat capacity, the standard enthalpy and standard Gibbs free energy of formation of EtOH, IB, 2M1B, 2M2B, ETBE and TAEE at $298 \mathrm{~K}$ are available in the literature, and they are listed in Table 2. Nonetheless, thermodynamic data for the formation of TAEE 
Table 2 - Liquid-phase thermochemical data and liquid-phase molar heat capacity equation coefficients, $C_{p_{j}}^{\circ}\left(\begin{array}{l} \\ \end{array} \mathbf{K}^{-1} \mathbf{m o l}^{-1}\right)=a_{j}+b_{j} T+c_{j} T^{2}+d_{j} T^{3}$, with $\mathbf{T}$ expressed in Kelvin.

\begin{tabular}{|c|c|c|c|c|c|c|}
\hline \multirow[t]{2}{*}{ Component $j$} & \multicolumn{4}{|c|}{ Heat capacity coefficients } & \multirow[t]{2}{*}{$\Delta_{f} G_{j}^{\circ}(\mathrm{kJ} / \mathrm{mol})$} & \multirow[t]{2}{*}{$\Delta_{f} H_{j}^{\circ}(\mathrm{kJ} / \mathrm{mol})$} \\
\hline & $a_{j}$ & $b_{j}$ & $c_{j}$ & $d_{j}$ & & \\
\hline IB & $35.44^{\mathrm{a}}$ & $0.802^{\mathrm{a}}$ & $-3.124 \times 10^{-3 a}$ & $5.045 \times 10^{-6 a}$ & $60.67^{a}$ & $-37.7^{a}$ \\
\hline $\mathrm{EtOH}$ & $29.01^{a}$ & $0.2697^{a}$ & $-5.658 \times 10^{-4 a}$ & $2.079 \times 10^{-6 a}$ & $-174.8^{a}$ & $-277.51^{a}$ \\
\hline ETBE & $148.48^{b}$ & $0.09^{b}$ & $5.058 \times 10^{-4 b}$ & $0^{b}$ & $-126.8^{a}$ & $-350.8^{c}$ \\
\hline $2 \mathrm{M} 1 \mathrm{~B}$ & $126.5^{d}$ & $-0.0609^{d}$ & $5.084 \times 10^{-4 d}$ & $1.692 \times 10^{-7 d}$ & $66.5^{e}$ & $-60.96^{e}$ \\
\hline $2 \mathrm{M} 2 \mathrm{~B}$ & $132.9^{d}$ & $-0.1475^{d}$ & $7.511 \times 10^{-4 d}$ & $-8.817 \times 10^{-8 d}$ & $60.0^{\mathrm{e}}$ & $-68.07^{e}$ \\
\hline TAEE & $180.08^{b}$ & $0.0169^{b}$ & $6.95 \times 10^{-4 b}$ & $0^{\mathrm{b}}$ & $-119.9^{\mathrm{a}, \mathrm{e}}$ & $-372.9^{\mathrm{a}, \mathrm{e}}$ \\
\hline $\begin{array}{l}\text { Data based on } \\
\text { a Gallant (1970) } \\
\text { b Zábranský et } \\
\text { c Sharonov et a } \\
\text { d Yaws (1992). } \\
\text { e TRC Thermod }\end{array}$ & tal valu & $86)$. & & & & \\
\hline
\end{tabular}

and ETBE are scarcely reported and in any case, the lack of agreement between sources led to a discrepancy between theoretically and experimentally obtained equilibrium constants.

For the sake of comparison, Tables 3 and 4 provide the values of experimental equilibrium constant values reported previously for the ETBE and TAEE synthesis in isolated systems, respectively. Also the equilibrium constants determined theoretically by means of the thermodynamic data available in Table 2 and those obtained experimentally in this work as the mean values at each temperature are included in Tables 3 and 4. Errors indicated by authors in these tables are referred to a $95 \%$ confidence interval.

A good agreement is observed between experimental equilibrium constants for ETBE formation reaction $\left(K_{1}\right)$ in the simultaneous synthesis and those obtained for the isolated system experimentally. Furthermore, the agreement of the equilibrium constants for TAEE synthesis reactions $\left(K_{2}, K_{3}\right.$ and $K_{4}$ ) was rather good as well, which confirms the equilibrium constants to be independent of the simultaneous reactions. On the whole, it seems reasonable that the equilibrium constants obtained for the simultaneous syntheses of ETBE and TAEE were practically the same as those of isolated reactions. Hence, it can be concluded that the simultaneous etherification reactions take place in the same extension as it could be expected from the thermodynamic data of the separated ETBE and TAEE formation reactions by etherification of EtOH. A larger difference between experimental and theoretical values was observed for R1, R2 and R3. It can be explained because the respective equilibrium constants are highly sensitive to the thermodynamic data used in the calculations. The influence of the enthalpy of formation, $\Delta_{f} H_{j}^{\circ}$, of a component $j$ in the equilibrium constant is of utmost importance; for instance, a deviation of $1 \mathrm{~kJ} / \mathrm{mol}$ in the enthalpy of formation of $2 \mathrm{M} 1 \mathrm{~B}$ changes the equilibrium constant of the $2 \mathrm{M} 1 \mathrm{~B}$ etherification reaction from 21 to 31, and changes the equi- librium constant of the isoamylenes isomerization reaction from 11 to 17. A similar difference in the absolute entropy of a component $j, S_{j}^{\circ}$ or $C_{p j}^{\circ}$ has a minor effect on the calculation of $K_{i}$.

Deviation in $K_{i}$ values due to the difference between the working pressure and the pressure at the standard state was evaluated by means of the product between $K_{i}$ and the Poynting correction factor $\mathrm{K}_{\Gamma i}$, which can be estimated by the following expression (Smith and Van Ness, 1987):

$\mathrm{K}_{\Gamma i}=\exp \left(\frac{\mathrm{P}-1}{\mathrm{RT}} \sum_{j=1}^{\mathrm{S}} v_{j i} \mathrm{~V}_{j}\right)$

where $V_{j}$ is the molar volume of compound $j$.

Molar volumes were calculated by HBT method (Reid et al., 1987) and $K_{\Gamma i}$ correction factors for the main four chemical reactions were approximately equal to unity (always higher than 0.9999). Consequently, it can be said that the effect of the working pressure on the calculated $K_{i}$ was negligible and, therefore, it can be assumed that the equilibrium constant is only a function of temperature.

The temperature dependence of the thermodynamic equilibrium constant is given by:

$\ln K_{i}=\frac{-\Delta_{r} G_{i}^{\circ}}{R T}=\frac{-\Delta_{r} H_{i}^{\circ}}{R T}+\frac{\Delta_{r} S_{i}^{\circ}}{R}$

At this point, two alternatives can be considered: (i) $\Delta_{r} H_{i}^{\circ}$ constant with temperature $\left(\Delta_{r} H_{i}^{\circ} \neq f(T)\right)$, and (ii) $\Delta_{r} H_{i}^{\circ}$ depends on temperature $\left(\Delta_{r} H_{i}^{\circ}=f(T)\right)$. On one hand, if the enthalpy change of reaction is assumed to be constant within the assayed temperature range, fitting Eq. (4) to the experimental equilibrium constant values should produce a straight line. Fig. 5 depicts $\ln K_{i}$ versus 1/T for the four experimental

Table 3 - Experimental equilibrium constants values for ETBE formation reaction (R1) and comparison with published results.

\begin{tabular}{|c|c|c|c|c|c|c|c|c|c|}
\hline & $\mathrm{T}(\mathrm{K})$ & This work & $\begin{array}{l}\text { Françoisse and } \\
\text { Thyrion (1991) }\end{array}$ & $\begin{array}{l}\text { Vila et al. } \\
\text { (1993) }\end{array}$ & $\begin{array}{l}\text { Cunill et al. } \\
\text { (1993) }\end{array}$ & $\begin{array}{c}\text { Izquierdo et al. } \\
\text { (1994) }\end{array}$ & $\begin{array}{l}\text { Jensen and } \\
\text { Datta (1995) }\end{array}$ & $\begin{array}{c}\text { Gómez } \\
\text { et al. (1997) }\end{array}$ & $\begin{array}{l}\text { Determined } \\
\text { theoretically }\end{array}$ \\
\hline \multirow[t]{4}{*}{$\mathrm{K}_{1}$} & 323 & $41.9 \pm 3.9$ & 46 & 42.1 & 41.5 & $40 \pm 7$ & 44 & $34.3 \pm 0.4$ & 54.6 \\
\hline & 333 & $28.4 \pm 3.3$ & 26 & 26.4 & 26.8 & $26 \pm 3$ & 27 & $22.3 \pm 1$ & 36.7 \\
\hline & 343 & $20.2 \pm 2.5$ & 16 & 18.4 & 18.1 & $18 \pm 1$ & 17 & $17.1 \pm 1.8$ & 25.3 \\
\hline & 353 & $13.1 \pm 1.2$ & 11.5 & 12.8 & 12.6 & $13 \pm 2$ & 11 & $11.3 \pm 0.7$ & 17.7 \\
\hline
\end{tabular}


Table 4 - Experimental equilibrium constant values for TAEE formation reactions (R2 and R3) and for isoamylenes isomerization reaction (R4) and comparison with published results.

\begin{tabular}{|c|c|c|c|c|c|c|c|}
\hline & $\mathrm{T}(\mathrm{K})$ & This work & $\begin{array}{l}\text { Rihko et al. } \\
\text { (1994) }\end{array}$ & $\begin{array}{c}\text { Kitchaiya and } \\
\text { Datta (1995) }\end{array}$ & $\begin{array}{c}\text { Cruz et al. } \\
\text { (2007) }\end{array}$ & $\begin{array}{l}\text { Fitó and } \\
\text { Linnekoski } \\
\text { (2008) }\end{array}$ & $\begin{array}{l}\text { Determined } \\
\text { theoretically }\end{array}$ \\
\hline \multirow[t]{4}{*}{$K_{2}$} & 323 & $29.3 \pm 1.6$ & $24.8 \pm 1.5$ & 30.6 & - & 31.1 & 36.7 \\
\hline & 333 & $20.5 \pm 1.3$ & $17.4 \pm 1.1$ & 20.8 & 20.6 & 20.9 & 25.0 \\
\hline & 343 & $14.4 \pm 1.3$ & $11.3 \pm 0.8$ & 14.7 & - & 14.5 & 17.4 \\
\hline & 353 & $9.6 \pm 0.8$ & $8.3 \pm 0.6$ & - & 8.0 & - & 12.4 \\
\hline \multirow[t]{4}{*}{$K_{3}$} & 323 & $2.3 \pm 0.2$ & $2.2 \pm 0.1$ & 2.6 & - & 2.6 & 3.4 \\
\hline & 333 & $1.7 \pm 0.1$ & $1.7 \pm 0.1$ & 1.9 & 2.1 & 1.9 & 2.5 \\
\hline & 343 & $1.3 \pm 0.1$ & $1.2 \pm 0.1$ & 1.5 & - & 1.5 & 1.8 \\
\hline & 353 & $1.0 \pm 0.1$ & $1.0 \pm 0.1$ & - & 1.2 & - & 1.4 \\
\hline \multirow[t]{4}{*}{$\mathrm{K}_{4}$} & 323 & $13.1 \pm 0.7$ & $11 \pm 0.4$ & 11.9 & - & 12.0 & 11.0 \\
\hline & 333 & $11.8 \pm 0.5$ & $10.2 \pm 0.4$ & 10.9 & - & 10.9 & 10.2 \\
\hline & 343 & $10.9 \pm 0.5$ & $9.3 \pm 0.4$ & 10.0 & - & 10.0 & 9.5 \\
\hline & 353 & $9.5 \pm 0.5$ & $8.6 \pm 0.4$ & - & - & - & 8.8 \\
\hline
\end{tabular}

equilibrium constants obtained. As it can be seen, experimental results fit quite well to a straight line.

The resulting fitting equations obtained by least squares regression are:

$$
\begin{aligned}
& \ln K_{1}=\left(\frac{4370 \pm 870}{T}\right)-(9.8 \pm 2.6) \\
& \ln K_{2}=\left(\frac{4220 \pm 730}{T}\right)-(9.7 \pm 2.2) \\
& \ln K_{3}=\left(\frac{3070 \pm 360}{T}\right)-(8.67 \pm 1.06) \\
& \ln K_{4}=\left(\frac{1170 \pm 460}{T}\right)-(1.04 \pm 1.36)
\end{aligned}
$$

The standard molar enthalpy change of reaction $\left(\Delta_{r} H_{i}^{\circ}\right)$ can be obtained from the slope and the standard molar entropy change of the reaction $\left(\Delta_{r} S_{i}^{\circ}\right)$ from the intercept. From the fitted parameters, the values of $\Delta_{r} H_{i}^{\circ}$ and $\Delta_{r} S_{i}^{\circ}$ have been estimated, as presented in Table 6.

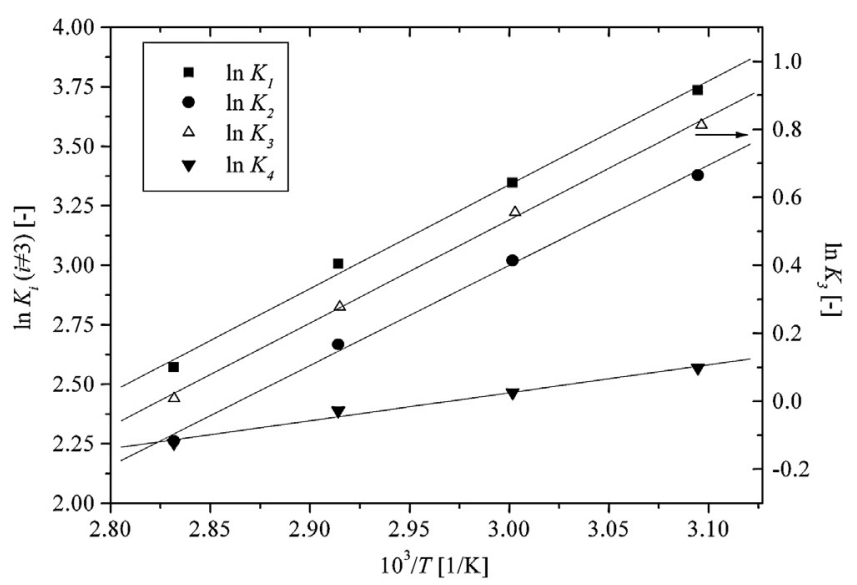

Fig. 5 - Van't Hoff plot for the case where the reaction enthalpy change is considered constant within the temperature range $\left(\Delta_{r} H_{i}^{\circ} \neq f(T)\right)$. Solid lines refer to the values predicted by Eqs. (5)-(8).
On the other hand, if $\Delta_{r} H_{i}^{\circ}$ is considered to change over the temperature range, its dependence can be expressed by the Kirchoff equation:

$\frac{d \Delta_{r} H_{i}^{\circ}}{d T}=\sum_{j=1}^{S} v_{i j} C_{p_{j}}^{\circ}$

where $C_{p j}^{\circ}$ are the molar heat capacities in the liquid phase of the compounds $j$ that take part in the reaction $i$, which can be estimated from equation and data included in Table 2 (Hamid and Ali, 2004).

Estimated values for molar heat capacity of ETBE with parameters from Table 2 were in agreement with those obtained by Solà et al. (1995), who estimated a value of $226.6 \mathrm{~J} /(\mathrm{mol} \mathrm{K})$ at $298 \mathrm{~K}$. Also the values obtained for TAEE are very similar to those reported by Kitchaiya and Datta (1995) at $298 \mathrm{~K}$, being 240 and $244 \mathrm{~J} /(\mathrm{mol} \mathrm{k})$ estimated by the Rowlinson method and from TRC Thermodynamic Tables, respectively. This difference in the estimation of heat capacities is acceptable, since calculations indicate that an error in the value of heat capacity of $10 \mathrm{~J} /(\mathrm{mol} \mathrm{K})$ introduced an error less than $1.5 \%$ into the calculated equilibrium constants for TAEE synthesis (Kitchaiya and Datta, 1995). The values of molar heat capacity obtained were also very similar to those estimated at $298 \mathrm{~K}$ by the Missenard method (Reid et al., 1987) for ETBE and TAEE. Henceforward, the coefficients from Table 2 were used in the calculations of the thermodynamic properties showed below.

The integrated form of the Kirchoff equation, combined with equations from Table 2, gives the following expression:

$\Delta_{r} H_{i}^{\circ}=I_{k}+a T+\frac{b}{2} T^{2}+\frac{c}{3} T^{3}+\frac{d}{4} T^{4}$

where:

$a=\sum_{j=1}^{S} v_{i j} a_{i} ; \quad b=\sum_{j=1}^{S} v_{i j} b_{i} ; \quad c=\sum_{j=1}^{S} v_{i j} c_{i} ; \quad d=\sum_{j=1}^{S} v_{i j} d_{i}$

The dependence of the equilibrium constant on temperature is described by the van't Hoff equation:

$\frac{d \ln K_{i}}{d T}=\frac{-\Delta_{r} H_{i}^{\circ}}{R T^{2}}$ 


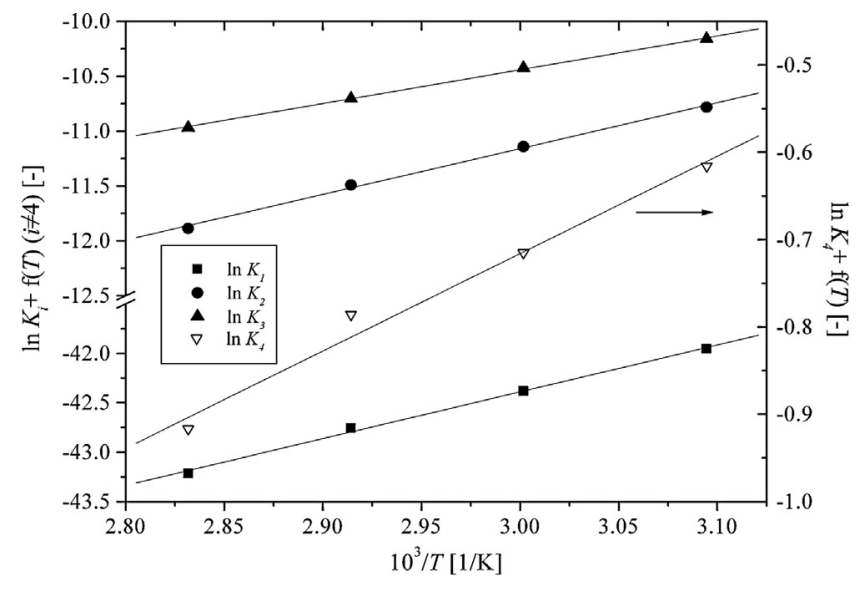

Fig. 6 - Van't Hoff plot for the case where the reaction enthalpy change is considered dependent on temperature $\left(\Delta_{r} H_{i}^{\circ}=f(T)\right)$.

This equation, combined with Eq. (10) and integrated, leads to:

$\ln K_{i}=I_{H}-\frac{I_{K}}{R T}+\frac{a}{R} \cdot \ln T+\frac{b}{2 R} T+\frac{c}{6 R} T^{2}+\frac{d}{12 R} T^{3}$

where $I_{K}$ and $I_{H}$ are the integration constants (unknown parameters).

By fitting Eq. (13) to the experimental values of the equilibrium constants at different temperatures (see Fig. 6 ), $I_{K}$ can be obtained from the slope and $I_{H}$ from the intercept. The fitting was accurate enough for both methods, assuming $\Delta_{r} H_{i}^{\circ}$ constant or variable. The linear fitting coefficient $R^{2}$ was always higher than 0.99 for each reaction with the exception of the value of 0.983 obtained for the isomerization reaction between isoamylenes.

The standard molar changes of reaction $\Delta_{r} S_{i}^{\circ}$ and $\Delta_{r} G_{i}^{\circ}$ can be evaluated, by means of Eqs. (4), (10) and (13), as follows:

$\Delta_{r} S_{i}^{\circ}(T)=R \cdot I_{H}+a+a \cdot \ln T+b T+\frac{c}{2} T^{2}+\frac{d}{3} T^{3}$

$\Delta_{r} G_{i}^{\circ}(T)=I_{K}-R \cdot I_{H} \cdot T-a \cdot T \cdot \ln T-\frac{b}{2} T^{2}-\frac{c}{6} T^{3}-\frac{d}{12} T^{4}$

Parameters of Eqs. (10), (13)-(15) are shown in Table 5.

Finally, the thermodynamic state functions $\Delta_{r} H_{i}^{\circ}, \Delta_{r} S_{i}^{\circ}$ and $\Delta_{r} G_{i}^{\circ}$ can also be computed theoretically from the thermodynamic data available in Table $2\left(\Delta_{f} H_{j}^{\circ}\right.$ and $\left.\Delta_{f} G_{j}^{\circ}\right)$ for the involved species by using Eq. (4) and the following expressions:

$\Delta_{r} H_{i}^{\circ}=\sum\left(v_{i j} \cdot \Delta_{f} H_{j}^{\circ}\right)$

$\Delta_{r} G_{i}^{\circ}=\sum\left(v_{i j} \cdot \Delta_{f} G_{j}^{\circ}\right)$

Table 6 is a summary of the experimentally and theoretically calculated thermodynamic changes for every reaction and considered hypothesis.

$\Delta_{f} H_{j}^{\circ}$ of TAEE obtained experimentally from equilibrium measurements by Sharonov et al. (1995) was not used in the theoretical calculations because it led to a high deviation between theoretical and experimental values of the thermodynamic reaction changes. Thus, its value of $-379.8 \mathrm{~kJ} / \mathrm{mol}$ for TAEE was refused accordingly with the data of Table 2, but not the value of $-350.8 \mathrm{~kJ} / \mathrm{mol}$ obtained for $\Delta_{f} H_{j}^{\circ}$ of ETBE in the same study. It can be observed in Table 6 that the obtained experimental thermodynamic state functions values are very close or within the range of the experimental ones reported previously for the isolated ether production reactions. Since all four molar enthalpy changes of reactions are negatives, all four chemical reactions are exothermic, as it was already mentioned earlier. A fair agreement is obtained between the experimental and the theoretical data, the larger differences being found in the isoamylenes isomerization reaction, but always within the experimental error.

On the whole, it seems that the negative values $\Delta_{r} H_{i}^{\circ}$ and $\Delta_{r} S_{i}^{\circ}$ increase in absolute value when more branched is the olefin for the mentioned etherification reactions using ethanol. Thus, the most ramified the olefin, the highest the exothermicity was observed. This fact agrees with results available in the literature, where a higher enthalpy change in the production of tert-hexyl ethyl ether (THEE) from 2-ethyl1-butene and ethanol than from the etherification of cis or trans-3-methyl-2-pentene with the same alcohol was reported (Zhang and Datta, 1996). Furthermore, concerning the reactions that involve $2 \mathrm{M} 1 \mathrm{~B}$ and $2 \mathrm{M} 2 \mathrm{~B}$, the enthalpy of reaction was lower when the double bond is not terminal (2M2B).

Due to the lack of information, especially for TAEE (and the lack of agreement between sources for both main produced ethers ETBE and TAEE), the experimental data obtained in this work were used to estimate the standard Gibbs free energy and molar enthalpy changes of formation for both ethers. The estimated values of $\Delta_{f} G_{j}^{\circ}$ for ETBE and TAEE, which were found to fit, better to the experimental values were -126.3 and $-119.2 \mathrm{~kJ} / \mathrm{mol}$, respectively. Analogously, the estimated $\Delta_{f} H_{j}^{\circ}$ for ETBE and TAEE were -351.5 and $-372.3 \mathrm{~kJ} / \mathrm{mol}$, respectively. The difference between these proposed enthalpies of formation and those estimated by improved Benson group additive method (Verevkin, 2002) are less than 1\%. Using this data, both theoretical equilibrium constants and thermodynamic state functions are more similar to the experimental values of this study.

Considering that the molar reaction enthalpy change is not constant over the temperature range, it is interesting to see its variation with the temperature. Such values are presented in Table 7 for all four chemical equilibrium reactions. From the variation of $\Delta_{r} H_{i}^{\circ}$, it can be said that the reaction enthalpy hardly varies in the assayed temperature range. Therefore, it has been concluded that $\Delta_{r} H_{i}^{\circ}$ can be considered constant over the temperature range.

The values for the ETBE synthesis in Table 7 are quite close to those determined by Vila et al. (1993) and by Solà et al. (1995), who predicted an enthalpy variation from -34.8 to $-35.9 \mathrm{~kJ} / \mathrm{mol}$ and from -32 to $-35.8 \mathrm{~kJ} / \mathrm{mol}$, respectively, in the temperature range from 298 to $333 \mathrm{~K}$. For TAEE synthesis reactions (R2-R4) between 323 and $353 \mathrm{~K}$, a fair agreement is also observed with values reported previously in literature by Rihko et al. (1994), who determined a variation of the molar standard enthalpy reaction between -34 and $-38 \mathrm{~kJ} / \mathrm{mol}$ for the TAEE synthesis from $2 \mathrm{M} 1 \mathrm{~B}$ and between -27 and $-31 \mathrm{~kJ} / \mathrm{mol}$ for TAEE synthesis from 2M2B.

In addition to the main reactions $\mathrm{R} 1-\mathrm{R} 4$, the isomerization reaction (hereafter named as $\mathrm{R} 5$ ) between both isobutene dimers, TMP-1 and TMP-2, has also been analyzed. The equilibrium constants of this isomerization reaction were calculated at the temperature range $323-353 \mathrm{~K}$ under the conditions that favored the $\mathrm{C}_{8}$ dimers formation, namely $\mathrm{R}_{\mathrm{A} / \mathrm{O}}=0.5$ and $R_{C 4 / C 5}=2$. Although $C_{8}$ dimers were also produced at $R_{\mathrm{A} / \mathrm{O}}=0.5, R_{\mathrm{C} 4 / \mathrm{C} 5}=1$ and $343-353 \mathrm{~K}$, the low amount at which they were detected made difficult to study the chemical equilibrium in the whole range of the assayed temperatures and 
Table 5 - Temperature dependence parameters of $\mathbf{K}_{\mathbf{i}}, \Delta_{r} H_{i}^{\circ}, \Delta_{r} S_{i}^{\circ}$ and $\Delta_{r} G_{i}^{\circ}$ for reactions R1 to R4 when $\Delta_{r} H_{i}^{\circ}=f(T)$.

\begin{tabular}{lcccc} 
Parameters & R1 & R2 & R3 & R4 \\
\hline$a(J / m o l ~ K)$ & 84.0282 & 24.5698 & 18.1698 & 6.4 \\
$b\left(J / \mathrm{mol} \mathrm{K}^{2}\right)$ & -0.9817 & -0.1919 & -0.1053 & -0.0866 \\
$c\left(J / \mathrm{mol} \mathrm{K}^{3}\right)$ & 0.0042 & 0.000752 & 0.00051 & 0.000243 \\
$d\left(\mathrm{~J} / \mathrm{mol} \mathrm{K}^{4}\right)$ & $-7.1 \times 10^{-6}$ & $-2.25 \times 10^{-6}$ & $-1.99 \times 10^{-6}$ & $-2.57 \times 10^{-7}$ \\
$I_{k}(\mathrm{~J} / \mathrm{mol})$ & $-39,414.5$ & $-34,760.44$ & $-25,696.08$ & -9215.31 \\
$I_{H}(-)$ & -56.61 & -23.70 & -19.71 & -4.04 \\
\hline
\end{tabular}

Table 6 - Summary of thermochemical properties of reactions at $298 \mathrm{~K}$ and comparison with values reported in literature. Errors refer to a $95 \%$ confidence interval.

\begin{tabular}{|c|c|c|c|c|c|c|c|c|}
\hline Reaction & Properties & Case $\Delta_{r} H_{i}^{\circ} \neq f(T)$ & Case $\Delta_{r} H_{i}^{\circ}=f(T)$ & Theoret. & Literature data & & & \\
\hline R1 & $\begin{array}{l}\Delta_{r} H_{1}^{\circ}(\mathrm{kJ} / \mathrm{mol}) \\
\Delta_{r} S_{1}^{\circ}(\mathrm{J} / \mathrm{mol} \mathrm{K}) \\
\Delta_{r} G_{1}^{\circ}(\mathrm{kJ} / \mathrm{mol})\end{array}$ & $\begin{array}{l}-36.3 \pm 7.2 \\
-81.3 \pm 21.4 \\
-12.1 \pm 4.5\end{array}$ & $\begin{array}{l}-35.0 \pm 6.7 \\
-77.1 \pm 20.0 \\
-12.0 \pm 6.7\end{array}$ & $\begin{array}{l}-35.6 \\
-76.9 \\
-12.7\end{array}$ & $\begin{array}{l}-34.8 \pm 1.3^{\mathrm{a}} \\
-77.3 \pm 0.6^{\mathrm{a}} \\
11.8 \pm 1.3^{\mathrm{a}}\end{array}$ & $\begin{array}{l}-35.5 \pm 2^{b} \\
-82.4 \pm 6^{b} \\
-\end{array}$ & $\begin{array}{l}-36 \pm 2^{\mathrm{c}} \\
- \\
-\end{array}$ & $\begin{array}{l}-44.3^{\mathrm{d}} \\
- \\
-\end{array}$ \\
\hline R2 & $\begin{array}{l}\Delta_{r} H_{2}^{\circ}(\mathrm{kJ} / \mathrm{mol}) \\
\Delta_{r} \mathrm{~S}_{2}^{\circ}(\mathrm{J} / \mathrm{mol} \mathrm{K}) \\
\Delta_{r} G_{2}^{\circ}(\mathrm{kJ} / \mathrm{mol})\end{array}$ & $\begin{array}{l}-35.1 \pm 6.0 \\
-80.3 \pm 17.9 \\
-11.1 \pm 2.7\end{array}$ & $\begin{array}{l}-33.8 \pm 5.5 \\
-76.1 \pm 16.3 \\
-11.1 \pm 5.5\end{array}$ & $\begin{array}{l}-34.4 \\
-76.5 \\
-11.6\end{array}$ & $\begin{array}{l}-33.6^{\mathrm{e}} \\
-75.4^{\mathrm{e}} \\
-11.1^{\mathrm{e}}\end{array}$ & $\begin{array}{l}-35.2 \pm 5.8^{\mathrm{f}} \\
-82.3 \pm 17.3^{\mathrm{f}} \\
-10.7^{\mathrm{e}}\end{array}$ & $\begin{array}{l}-34.9 \\
-80.9 \\
-10.9\end{array}$ & $\begin{array}{l}- \\
- \\
-\end{array}$ \\
\hline R3 & $\begin{array}{l}\Delta_{r} H_{3}^{\circ}(\mathrm{kJ} / \mathrm{mol}) \\
\Delta_{r} S_{3}^{\circ}(\mathrm{J} / \mathrm{mol} \mathrm{K}) \\
\Delta_{r} G_{3}^{\circ}(\mathrm{kJ} / \mathrm{mol})\end{array}$ & $\begin{array}{l}-25.5 \pm 3.0 \\
-72.1 \pm 8.8 \\
-4.0 \pm 4.7\end{array}$ & $\begin{array}{l}-24.4 \pm 2.5 \\
-68.6 \pm 7.4 \\
-4.0 \pm 2.5\end{array}$ & $\begin{array}{l}-27.3 \\
-74.5 \\
-5.1\end{array}$ & $\begin{array}{l}-24.2^{\mathrm{e}} \\
-67^{\mathrm{e}} \\
-4.1^{\mathrm{e}}\end{array}$ & $\begin{array}{l}-27.3 \pm 6.7^{\mathrm{f}} \\
-77.8 \pm 19.8^{\mathrm{f}} \\
-4.1^{\mathrm{f}}\end{array}$ & $\begin{array}{l}-2^{g} \\
-76.9 \\
-4 . .^{g}\end{array}$ & $\begin{array}{l}-27.7 \pm 0^{h} \\
- \\
-\end{array}$ \\
\hline R4 & $\begin{array}{l}\Delta_{r} H_{4}^{\circ}(\mathrm{kJ} / \mathrm{mol}) \\
\Delta_{r} S_{4}^{\circ}(\mathrm{J} / \mathrm{mol} \mathrm{K}) \\
\Delta_{r} G_{4}^{\circ}(\mathrm{kJ} / \mathrm{mol})\end{array}$ & $\begin{array}{l}-9.7 \pm 3.8 \\
-8.6 \pm 11.3 \\
-7.1 \pm 2.5\end{array}$ & $\begin{array}{l}-9.5 \pm 3.8 \\
-8.0 \pm 11.2 \\
-7.1 \pm 3.8\end{array}$ & $\begin{array}{l}-7.1 \\
-2.0 \\
-6.5\end{array}$ & $\begin{array}{l}-9.16^{\mathrm{e}} \\
-7.48^{\mathrm{e}} \\
-6.93^{\mathrm{e}}\end{array}$ & $\begin{array}{l}-8 \pm 1.4^{\mathrm{f}} \\
-4.7 \pm 4.2^{\mathrm{f}} \\
-6.6^{\mathrm{f}}\end{array}$ & $\begin{array}{l}-8.8 \pm 2.7^{\mathrm{i}} \\
-4.1 \pm 7.8^{\mathrm{i}} \\
-7.1 \pm 11.7^{\mathrm{k}}\end{array}$ & $\begin{array}{l}-9.5^{j} \\
-10 \pm 6.6^{k} \\
-6.8^{j}\end{array}$ \\
\hline $\begin{array}{ll}\text { a } & \text { Vila et al } \\
\text { b Sharono } \\
\text { c Gómez e } \\
\text { d François } \\
\text { e Kitchaiy } \\
\text { f Rihko et } \\
\text { g Linnekos } \\
\text { h Verevkin } \\
\text { i Ferreira } \\
\text { j Syed et a } \\
\text { k Mao et a }\end{array}$ & $\begin{array}{l}\text { 993). } \\
\text { t al. (1995). } \\
\text { l. (1997). } \\
\text { and Thyrion (19 } \\
\text { nd Datta (1995) } \\
\text { (1994). } \\
\text { et al. (1999). } \\
\text { 004). } \\
\text { d Loureiro (2004 } \\
\text { (2000). } \\
\text { 2008). }\end{array}$ & 91). & & & & & & \\
\hline
\end{tabular}

\section{Table 7 - Estimated values of the standard molar enthalpy of reaction, $\Delta_{r} H_{i}^{\circ}$, for reactions $\mathbf{R} 1$ to $\mathbf{R} 4$, when it is considered} as temperature dependent.

\begin{tabular}{lcccc}
$\mathrm{T}(\mathrm{K})$ & $\Delta_{\mathrm{r}} \mathrm{H}_{1}^{\circ}(\mathrm{kJ} / \mathrm{mol})$ & $\Delta_{r} \mathrm{H}_{2}^{\circ}(\mathrm{kJ} / \mathrm{mol})$ & $\Delta_{r} \mathrm{H}_{3}^{\circ}(\mathrm{kJ} / \mathrm{mol})$ & $\Delta_{r} \mathrm{H}_{4}^{\circ}(\mathrm{kJ} / \mathrm{mol})$ \\
\hline 323 & -35.8 & -34.5 & -25.0 & -9.6 \\
333 & -36.1 & -34.9 & -25.3 & -9.7 \\
343 & -36.6 & -35.3 & -25.7 & -9.7 \\
353 & -37.1 & -35.8 & -26.1 & -9.8 \\
\hline
\end{tabular}

with the required accuracy. For the appropriate experiments, the equilibrium constant of R5 was estimated through the same procedure as described above for the calculations of activity coefficients. Obtained results are presented in Table 8.

Equilibrium constants from Table 8 are comparable to those reported in a specific study of the isomerization reaction between both trimethylpentenes, TMP-1 and TMP-2 (Karinen et al., 2001b). $K_{x 5}$ ranged from 0.242 to 0.286 and $K_{\gamma 5}$ hardly changed in the temperature range from 1.018 to 1.019 , which

Table 8 - Experimental values of equilibrium constant for the double bond isomerization reaction of

trimethylpentenes (R5).

\begin{tabular}{lcc}
$T(\mathrm{~K})$ & $\mathrm{K}_{5}$ (this work) & $\mathrm{K}_{5}$ (Karinen et al., 2001) \\
\hline 323 & 0.246 & 0.256 \\
333 & 0.262 & 0.267 \\
343 & 0.274 & 0.277 \\
353 & 0.292 & 0.286
\end{tabular}

are very close to the unity, as expected, because only two similar olefins are involved in this reaction. $K_{x 5}$ and $K_{\gamma 5}$ increased at increasing temperature. Consequently, it can be said that this isomerization reaction is slightly endothermic. The molar enthalpy and entropy changes of reaction $\left(\Delta_{r} H_{5}^{\circ}\right.$ and $\left.\Delta_{r} S_{5}^{\circ}\right)$ were calculated by assuming that the enthalpy change is constant over the temperature range, by means of Eq. (4). The case in which $\Delta_{r} H_{5}^{\circ}$ varies with temperature has not been considered because when the temperature range is small or the $C_{p j}^{\circ}$ functions of the molecules are close to each other, as is the case between these $\mathrm{C}_{8}$ dimers, the results are practically the same as for $\Delta_{r} H_{5}^{\circ}$ considered constant over the temperature range. From the experimental data linear regression, the following dependence of the equilibrium constant with temperature was found:

$\ln K_{5}=\left(\frac{-637 \pm 101}{T}\right)+(0.57 \pm 0.30)$ 
Values of $\Delta_{r} H_{5}^{\circ}=(5.3 \pm 0.8) \mathrm{kJ} / \mathrm{mol}$ and $\Delta_{r} S_{5}^{\circ}=(4.7 \pm$ 2.5) $\mathrm{J} /(\mathrm{mol} \mathrm{K})$ were obtained, with a correlation coefficient $R^{2}$ higher than 0.997. Slightly different values were found by Karinen et al. (2001b), who reported experimental values of $3.51 \mathrm{~kJ} / \mathrm{mol}$ for $\Delta_{r} H_{5}^{\circ}$ and $0.47 \mathrm{~J} /(\mathrm{mol} \mathrm{K})$ for $\Delta_{r} S_{5}^{\circ}$. However, obtained values in this work are consistent with those determined experimentally by Parks et al. (1936) who found values of $\Delta_{r} H_{5}^{\circ}=4.65 \mathrm{~kJ} / \mathrm{mol}$ and $\Delta_{r} S_{5}^{\circ}=5.44 \mathrm{~J} /(\mathrm{mol} \mathrm{K})$. Besides, Turner et al. (1958) published an experimental value of $5.4 \mathrm{~kJ} / \mathrm{mol}$ for the enthalpy change of reaction, nearby the same value obtained in this work. The similarity between results and the good fit obtained from experimental data for this isomerization reaction between trimethylpentenes enforces the reliability of the present study.

\section{Conclusions}

The thermodynamics of the involved reactions have been proven to be independent of the simultaneous process when activities are used for calculations. All four main chemical reactions in the ETBE and TAEE formation network have been found to be reversible and exothermic. Consequently, the amount of produced ethers at equilibrium decreases when temperature increases. Optimum conditions for maximizing both ethers formation are at low temperature and at $R_{A / O}$ and $R_{C 4 / C 5}$ values close to unity. $R_{C 4 / C 5}$ can be varied depending on which ether formation is preferred. As expected, no significant effect on the equilibrium state has been observed when using different catalysts, namely A-35, A-15 and CT-275.

The exothermicity of the etherification reactions (R1-R3) is higher than that of IA isomerization reaction (R4). ETBE formation (R1) was found to be the most exothermic reaction, followed by the TAEE formation from $2 \mathrm{M} 1 \mathrm{~B}$ (R2) and from $2 \mathrm{M} 2 \mathrm{~B}(\mathrm{R} 3)$. It can be explained by the stability of alkene involved in each reaction. Consequently, the higher the olefin size, the lower the equilibrium constant of the etherification reactions. For reactions R1, R2, R3 and R4, molar standard enthalpy changes of $-36.3 \pm 7.2,-35.1 \pm 6.0,-25.5 \pm 3.0$ and $-9.7 \pm 3.8 \mathrm{~kJ} / \mathrm{mol}$ were determined, respectively. Therefore, the more branched the olefin, the higher the exothermicity. The chemical equilibrium between the two IB dimers, TMP-1 and TMP-2, was also studied and a molar enthalpy change of reaction value of $5.3 \pm 0.8 \mathrm{~kJ} / \mathrm{mol}$ was obtained.

There is an excellent agreement between the obtained molar standard enthalpies, entropies and Gibbs free energy changes of reactions with those quoted in open literature for the isolated ETBE and TAEE formation reactions. Nevertheless, from the small dispersion of the values, especially in theoretical and experimental equilibrium constants, more experimental work is needed in order to ascertain more reliable and precise data. Under this purpose, the standard molar enthalpies of formation for ETBE and TAEE were estimated from experimental data obtaining values of -351.5 and $-372.3 \mathrm{~kJ} / \mathrm{mol}$, respectively.

\section{Acknowledgements}

The authors are grateful to Rohm and Haas and Purolite for providing the ion-exchange resins used in this work.

\section{Appendix A. Supplementary data}

Supplementary data associated with this article can be found, in the online version, at doi:10.1016/j.cherd.2013.11.012.

\section{References}

Ahmed, F.E., 2001. Toxicology and human health effects following exposure to oxygenated or reformulated gasoline. Toxicol. Lett. 123, 89-113.

Aiouache, F., Goto, S., 2003. Sorption effect on kinetics of etherification of tert-amyl alcohol and ethanol. Chem. Eng. Sci. 58, 2065-2077.

Arteconi, A., Mazzarini, A., Nicola, G., 2011. Emissions from ethers and organic carbonate fuel additives: a review. Water Air Soil Pollut. 221, 405-423.

Boonthamtirawuti, O., Kiatkittipong, W., Arpornwichanop, A., Praserthdam, P., Assabumrungrat, S., 2009. Kinetics of liquid phase synthesis of tert-amyl ethyl ether from tert-amyl alcohol and ethanol over Amberlyst 16. J. Ind. Eng. Chem. 15, 451-457.

Boz, N., Dogu, T., 2005. Reflux-recycle-reactor for high yield and selectivity in TAME and TAEE production. AIChE J. 51, 631-640.

Boz, N., Dogu, T., Murtezaoglu, K., Dogu, G., 2005. Mechanism of TAME and TAEE synthesis from diffuse-reflectance FTIR analysis. Catal. Today 100, 419-424.

Bozga, G., Motelica, A., Dima, R., Plesu, V., Toma, A., Simion, C., 2008. Evaluation of published kinetic models for tert-amyl ethyl ether synthesis. Chem. Eng. Process. Process Intensif. 47, 2247-2255.

Cataluña, R., da Silva, R., de Menezes, E.W., Ivanov, R.B., 2008. Specific consumption of liquid biofuels in gasoline fuelled engines. Fuel 87, 3362-3368.

Cruz, V.J., Izquierdo, J.F., Cunill, F., Tejero, J., Iborra, M., Fité, C., 2005. Acid ion-exchange resins catalysts for the liquid-phase dimerization/etherification of isoamylenes in methanol or ethanol presence. React. Funct. Polym. 65, 149-160.

Cruz, V.J., Izquierdo, J.F., Cunill, F., Tejero, J., Iborra, M., Fité, C. Bringué, R., 2007. Kinetic modelling of the liquid-phase dimerization of isoamylenes on Amberlyst 35. React. Funct. Polym. 67, 210-224

Cunill, F., Vila, M., Izquierdo, J.F., Iborra, M., Tejero, J., 1993. Effect of water presence on methyl tert-butyl ether and ethyl tert-butyl ether liquid-phase syntheses. Ind. Eng. Chem. Res. 32, 564-569.

Degirmenci, L., Oktar, N., Dogu, G., 2009. Product distributions in ethyl tert-butyl ether synthesis over different solid acid catalysts. Ind. Eng. Chem. Res. 48, 2566-2576.

Dogu, T., Varisli, D., 2007. Alcohols as alternatives to petroleum for environmentally clean fuels and petrochemicals. Turk. J. Chem. 31, 551-567.

Ferreira, M.V., Loureiro, J.M., 2004. Number of actives sites in TAME synthesis: mechanism and kinetic modeling. Ind. Eng. Chem. Res. 43, 5156-5165.

Fité, C., Iborra, M., Tejero, J., Izquierdo, J.F., Cunill, F., 1994. Kinetics of the liquid-phase synthesis of ethyl tert-butyl ether (ETBE). Ind. Eng. Chem. Res. 33, 581-591.

Fitó, A., Linnekoski, J.A., 2008. Equilibrium of Simultaneous tert-Amyl Ethyl Ether and tert-Amyl Alcohol Formation Reactions. Helsinki University of Technology (PhD Thesis).

Françoisse, O., Thyrion, F.C., 1991. Kinetics and mechanism of ethyl tert-butyl ether liquid-phase synthesis. Chem. Eng. Process. Process Intensif. 30, 141-149.

Gallant, R.W., 1970. Physical Properties of Hydrocarbons, vol. 1. Gulf Publishing, Houston.

Gmehling, J., Li, J., Schiller, M., 1993. A modified UNIFAC model 2. Present parameter matrix and results for different thermodynamic properties. Ind. Eng. Chem. Res. 32, 178-193.

Gmehling, J., Lohmann, J., Jakob, A., Li, J., Joh, R., 1998. A modified UNIFAC (Dortmund) model 3. Revision and extension. Ind. Eng. Chem. Res. 37, 4876-4882.

Gómez, C., Cunill, F., Iborra, M., Izquierdo, F., Tejero, J., 1997. Experimental study of the simultaneous synthesis of methyl tert-butyl ether and ethyl tert-butyl ether in liquid phase. Ind. Eng. Chem. Res. 36, 4756-4762. 
González, R., 2011. Performance of Amberlyst 35 in the Synthesis of ETBE from Ethanol and C4 Cuts. University of Barcelona (PhD Thesis)

Hamid, H., Ali, M.A., 2004. Handbook of MTBE and Other Gasoline Oxygenates. Marcel Dekker Inc., New York.

Iborra, M., Tejero, J., El-Fassi, M.B., Cunill, F., Izquierdo, J.F., Fité, C., 2002. Experimental study of the liquid-phase simultaneous syntheses of methyl tert-butyl ether (MTBE) and tert-butyl alcohol (TBA). Ind. Eng. Chem. Res. 41, 5359-5365.

Izquierdo, J.F., Cunill, F., Vila, M., Iborra, M., Tejero, J., 1994 Equilibrium constants for methyl tert-butyl ether and ethyl tert-butyl ether liquid-phase syntheses using C4 olefinic cut. Ind. Eng. Chem. Res. 33, 2830-2835.

Jensen, K.L., Datta, R., 1995. Ethers from ethanol. 1. Equilibrium thermodynamic analysis of the liquid-phase ethyl tert-butyl ether reaction (ETBE). Ind. Eng. Chem. Res. 34, 392-399.

Karinen, R.S., Linnekoski, J.A., Krause, A.O.I., 2001a. Etherification of C5- and C8-alkenes with C1- to C4-alcohols. Catal. Lett. 76, 81-87.

Karinen, R.S., Lylykangas, M.S., Krause, A.O.I., 2001b. Reaction equilibrium in the isomerization of 2,4,4-trimethyl pentenes. Ind. Eng. Chem. Res. 40, 1011-1015.

Kiatkittipong, W., Thipsunet, P., Goto, S., Chaisuk, C., Praserthdam, P., Assabumrungrat, S., 2008. Simultaneous enhancement of ethanol supplement in gasoline and its quality improvement. Fuel Process. Technol. 89, 1365-1370.

Kiatkittipong, W., Yoothongkham, K., Chaisuk, C., Praserthdam, P., Goto, S., Assabumrungrat, S., 2009. Self-etherification process for cleaner fuel production. Catal. Lett. 128, 154-163.

Kiatkittipong, W., Wongsakulphasatch, S., Tintan, N., Laosiripojana, N., Praserthdam, P., Assabumrungrat, S., 2011. Gasoline upgrading by self-etherification with ethanol on modified beta-zeolite. Fuel Process. Technol. 92, 1999-2004.

Kitchaiya, P., Datta, R., 1995. Ethers from ethanol 2. Reaction equilibria of simultaneous tert-amyl ethyl ether synthesis and isoamylene isomerization. Ind. Eng. Chem. Res. 34, 1092-1101.

Kiviranta-Pääkkönen, P., Struckmann, L.K., Linnekoski, J.A., Krause, A.O.I., 1998. Dehydration of the alcohol in the etherification of isoamylenes with methanol and ethanol. Ind. Eng. Chem. Res. 37, 18-24.

Krause, A.O.I., Hammarström, L.G., 1987. Etherification of isoamylenes with methanol. Appl. Catal. 30, 313-324.

Linnekoski, J.A., Krause, A.O.I., Rihko, L.K., 1997. Kinetics of the heterogeneously catalyzed formation of tert-amyl ethyl ether. Ind. Eng. Chem. Res. 36, 310-316.

Linnekoski, J.A., Krause, A.O.I., Struckmann, L.K., 1998. Etherification and hydration of isoamylenes with ion exchange resin. Appl. Catal., A 170, 117-126.

Linnekoski, J.A., Kiviranta-Pääkkönen, P., Krause, A.O.I., Rihko-Struckmann, L., 1999. Simultaneous isomerization and etherification of isoamylenes. Ind. Eng. Chem. Res. 38, 4563-4570.

Lohmann, J., Joh, R., Gmehling, J., 2001. From UNIFAC to modified UNIFAC (Dortmund). Ind. Eng. Chem. Res. 40, 957-964.

Mao, W., Wang, X., Wang, H., Chang, H., Zhang, X., Han, J., 2008. Thermodynamic and kinetic study of tert-amyl methyl ether (TAME) synthesis. Chem. Eng. Process. Process Intensif. 47, 761-769.

Muja, I., Toma, A., Popescu, D.C., Ivanescu, I., Stanisteanu, V., 2005. Thermodynamic study of the methanol addition to isoamylen. Chem. Eng. Process. Process Intensif. 44, 645-651.

Oktar, N., Mürtezaoglu, K., Dogu, G., Dogu, T., 1999a. Dynamic analysis of adsorption equilibrium and rate parameters of reactants and products in MTBE, ETBE and TAME production. Can. J. Chem. Eng. 77, 406-412.

Oktar, N., Mürtezaoglu, K., Dogu, G., Gönderten, I., Dogu, T., 1999b. Etherification rates of 2-methyl-2-butene and 2-methyl-1-butene with ethanol for environmentally clean gasoline production. J. Chem. Technol. Biotechnol. 74, 155-161.

Pääkkönen, P.K., Krause, A.O.I., 2003. Diffusion and chemical reaction in isoamylene etherification within a cation-exchange resin. Appl. Catal., A 245, 289-301.
Parks, G.S., Todd, S.S., Shomate, C.H., 1936. Thermal data on organic compounds XVII. Some heat capacity, entropy and free energy data for five higher olefins. J. Am. Chem. Soc. 58, 2505-2508.

Reid, R.C., Praustnitz, J.M., Poiling, B.E., 1987. The Properties of Gases and Liquids, fourth ed. McGraw Hill, New York.

Rihko, L.K., Krause, A.O.I., 1993. Reactivity of isoamylenes with ethanol. Appl. Catal., A 101, 283-295.

Rihko, L.K., Linnekoski, J.A., Krause, A.O.I., 1994. Reaction equilibria in the synthesis of 2-methoxy-2-methylbutane and 2-ethoxy-2-methylbutane in the liquid phase. J. Chem. Eng. Data 39, 700-704.

Rihko, L.K., Krause, A.O.I., 1995. Kinetics of heterogeneously catalyzed tert-amyl methyl ether reactions in the liquid phase. Ind. Eng. Chem. Res. 34, 1172-1180.

Rihko, L.K., Krause, A.O.I., 1996. Etherification of FCC light gasoline with methanol. Ind. Eng. Chem. Res. 35, 2500-2507.

Rihko, L.K., Kiviranta-Pääkkönen, P.K., Krause, A.O.I., 1997. Kinetic model for the etherification of isoamylenes with methanol. Ind. Eng. Chem. Res. 36, 614-621.

Rock, K.L., de Cardenas, T., Fornoff, L., 1992. C5 olefins. The new refinery challenge. Fuel Reformulation 2, 42-48.

Rock, K.L., Korpelshoek, M., 2008. Increasing refinery biofuels production. PTQ Catal. 13, 45-50.

Serdá, J.A., Izquierdo, J.F., Tejero, J., Cunill, F., Iborra, M., 1995. Equilibrium and thermodynamics for

2-methyl-2-methoxybutane liquid-phase decomposition. Thermochim. Acta 259, 111-120.

Sharonov, K.G., Rozhnov, A.M., Korol'kov, A.V., Karaseva, S.Y., Miroshnichenko, E.A., Korchatova, L.I., 1995. Enthalpies of formation of 2-methyl-2-ethoxypropane and 2-ethyl-2-ethoxypropane from equilibrium measurements. J. Chem. Thermodyn. 27, 751-753.

Smith, J.M., Van Ness, H.C., 1987. Introduction to Chemical Engineering Thermodynamics. McGraw Hill, New York.

Solà, L., Pericàs, M.A., Cunill, F., Tejero, J., 1995. Thermodynamic and kinetic studies of the liquid phase synthesis of tert-butyl ethyl ether using a reaction calorimeter. Ind. Eng. Chem. Res. 34, 3718-3725.

Solà, L., Pericàs, M.A., Cunill, F., Izquierdo, J.F., 1997. A Comparative thermodynamic and kinetic study of the reaction between olefins and light alcohols leading to branched ethers. Reaction calorimetry study of the formation of tert-amyl methyl ether (TAME) and tert-butyl isopropyl ether (IPTBE). Ind. Eng. Chem. Res. 36, 2012-2018.

Solomons, T.W.G., Fryhle, C.B., 2000. Organic Chemistry. John Wiley and Sons, New York.

Syed, F.H., Egleston, C., Datta, R., 2000. Tert-amyl methyl ether (TAME). Thermodynamic analysis of reaction equilibria in the liquid phase. J. Chem. Eng. Data 45, 319-323.

TRC Thermodynamic Tables, 1986. Thermodynamics Research Center, The Texas A\&M University System, College Station, vol. 5, pp. 6090-6091.

Turner, R.B., Nettleton, D.E., Perelman, M., 1958. Heats of hydrogenation VI. Heats of hydrogenation of some substituted ethylenes. J. Am. Chem. Soc. 80, 1430-1433.

Umar, M., Saleemi, A.R., Qaiser, S., 2008. Synthesis of ethyl tert-butyl ether with tert-butyl alcohol and ethanol on various ion exchange resin catalysts. Catal. Commun. 9, 721-727.

Verevkin, S.P., 2002. Improved benson increments for the estimation of standard enthalpies of formation and enthalpies of vaporization of alkyl ethers, acetals, ketals, and ortho esters. J. Chem. Eng. Data 47, 1071-1097.

Verevkin, S.P., 2004. Thermochemistry of branched ethers: experimental study of chemical equilibrium in the reacting system of tert-amyl alkyl ether synthesis. J. Chem. Eng. Data 49, 576-581.

Vila, M., Cunill, F., Izquierdo, J.F., Tejero, J., Iborra, M., 1993. Equilibrium constants for ethyl tert-butyl ether liquid phase synthesis. Chem. Eng. Commun. 124, 223-232.

Vila, M., Cunill, F., Izquierdo, J.F., González, J., Hernández, A., 1994. The role of by-products formation in methyl tert-butyl ether 
synthesis catalyzed by a macroporous acidic resin. Appl. Catal., A 117, L99-L108.

Weidlich, U., Gmehling, J., 1987. A modified UNIFAC model. 1. Prediction of VLE, hE, and gamma infin. Ind. Eng. Chem. Res. 26, 1372-1381.

Yang, B., Yang, S., Yao, R., 2000. Synthesis of ethyl tert-butyl ether from tert-butyl alcohol and ethanol on strong acid cation-exchange resins. React. Funct. Polym. 44, 167-175.

Yaws, C.L., 1992. Thermodynamic and Physical Property Data. Gulf Publishing Co., Houston

Yee, K.F., Mohamed, A.R., Tan, S.H., 2013. A review on the evolution of ethyl tert-butyl ether (ETBE) and its future prospects. Renew. Sustain. Energy Rev. 22, 604-620.
Zábranský, M., Kolská, Z., Růžička Jr., V., Domalski, E.S., 2010. Heat capacity of liquids: critical review and recommended values. Supplement II. J. Phys. Chem. Ref. Data 39, 013103-1-013103-404.

Zhang, T., Datta, R., 1996. Ethers from ethanol-5. Equilibria and kinetics of the coupled reaction network of liquid-phase 3-methyl-3-ethoxy-pentane synthesis. Chem. Eng. Sci. 51, 649-661.

Zhang, T., Jensen, K., Kitchaiya, P., Phillips, C., Datta, R., 1997. Liquid-phase synthesis of ethanol-derived mixed tertiary alkyl ethyl ethers in an isothermal integral packed-bed reactor. Ind. Eng. Chem. Res. 36, 4586-4594. 